\title{
三氟乙基酮亚胺参与的催化不对称反应研究进展
}

\author{
孙忠文* 张聪聪陈丽君谢惠定柳波 刘丹丹* \\ (昆明医科大学药学院 云南省天然药物药理重点实验室 昆明 650500)
}

\begin{abstract}
摘要 氟原子或含氟基团在材料科学、药物化学等领域的生物活性分子中广泛存在. 三氟乙基酮亚胺同时存在高活性 亲电和亲核中心，是良好的 1,3-偶极子. 因其在催化不对称构建含有三氟甲基立体中心的反应中具有极高的研究价值 而备受关注. 以三氟乙基酮亚胺的底物和反应类型为主线，综述了近五年三氟乙基酮亚胺参与的催化不对称反应研究 进展，同时对该领域的未来发展进行了展望.

关键词 三氟乙基酮亚胺; 不对称催化; 环加成反应; 三氟甲基; 手性胺合成
\end{abstract}

\section{Recent Advances in Catalytic Asymmetric Reactions Involving Trifluoroethyl Ketimines}

\author{
Sun, Zhongwen* \\ Zhang, Congcong \\ Chen, Lijun \\ Xie, Huiding \\ Liu, Bo \\ Liu, Dandan* \\ (School of Pharmaceutical Science \& Yunnan Key Laboratory of Pharmacology for Natural Products, Kunming Medical Uni- \\ versity, Kunming 650500)
}

\begin{abstract}
The fluorine atoms or fluorine-containing groups are widely found in biologically molecules in the fields of materials science, pharmaceutical chemistry, etc. The properties of trifluoroethylketimines provide both electrophilic and nucleophilic centers, and become an excellent 1,3-dipole, which possessed high research value in catalytic asymmetric reactions of construction of trifluoromethyl stereocenters. Based on the substrates and reaction types of trifluoroethylketimine, the research progress of catalytic asymmetric reactions involving trifluoroethylketimine in recent five years is reviewed, and the future development of this field is prospected.
\end{abstract}

Keywords trifluoroethylketimine; asymmetric catalysis; cycloaddition; trifluoromethyl group; synthesis of chiral amine

三氟甲基 $\left(\mathrm{CF}_{3}\right)$ 是一类重要的氟代官能团，因其可 以改善和提升有机分子的酸碱度、亲脂性、代谢稳定性 以及渗透性等分子性能, 而在药物及有机化学领域备受 研究人员的关注 ${ }^{[1]}$. 尤其是三氟甲基手性中心已广泛存 在于多种生物活性分子、先导化合物以及上市药品结构 中[2](图 1), 表现出镇痛、抑制胆固醇吸收、抗症、抗癌 和抗人类免疫缺陷病毒(HIV)等活性. 例如: Efavirenz (1) $\left(\right.$ Sustiva $\left.{ }^{\mathrm{TM}}\right)$ 是一类著名抗逆转录病毒药物, 用于预防 和治疗人类免疫缺陷病毒(HIV)感染; DCP 083 (2)作为
HIV 病毒逆转录酶非核苷类抑制剂可用于治疗艾滋病; $\mathrm{CF}_{3}$-(MIF-1) (3)比不含三氟甲基的母体具有更好的镇痛 效果; $\mathrm{CF}_{3}$-蒿甲醚 $(4)\left(\mathrm{ED}_{50} 3.4 \mu \mathrm{mol} / \mathrm{kg}\right)$ 作为蒿甲醚 $\left(\mathrm{ED}_{50} 8.4 \mu \mathrm{mol} / \mathrm{kg}\right.$ ) 的修饰产物, 具有比蒿甲醚还要好的 抗症活性; CJ-17493 (5)作为新型的 NK-1 受体拮抗剂成 为治疗化疗引起的呕吐、关节炎及偏头痛等疾病的潜在 治疗药物; 黄体酮受体拮抗剂 6 结构中的三氟甲基使其 不仅具有抗孕激素活性，还具有部分雄性激素活性. 鉴 于三氟甲基在改善与提升药物性能等方面的作用，因

\footnotetext{
* Corresponding authors. E-mail: 527301858@qq.com; liudandan1017@qq.com

Received November 4, 2020; revised December 10, 2020; published online December 31, 2020.

Project supported by the National Natural Science Foundation of China (No. 21907044), the Yunnan Fundamental Research Projects (No. 2019FB124), the Yunnan Provincial Science and Technology Department-Kunming Medical University Applied Basic Research Joint Special Fund Project (No. 2017FE468(-138)), the Yunnan Provincial Department of Education Science Research Fund Project (No. 2016ZZX089) and the Open Fund of Key Laboratory of State Forestry and Grassland Adminstration on Highly-Efficient Utilization of Forestry Biomass Resources in Southwest China, Southwest Forestry University (Nos. 2019-KF18, 2020-KF06).

国家自然科学基金(No. 21907044)、云南省基础研究计划项目(No. 2019FB124)、云南省科技厅-昆明医科大学应用基础研究联合专项基金项目(No. 2017FE468(-138))、云南省教育厅科学研究基金(No. 2016ZZX089)和西南林业大学西南地区林业生物质高效利用国家林和草原局重点实验室开放基金 (Nos. 2019-KF18, 2020-KF06)资助项目.
} 
此, 合成光学纯的含三氟甲基化合物正成为众多药物学 家和化学家研究的目标.

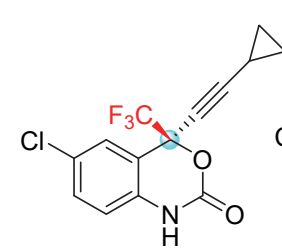

Efavirenz (1) prevents HIV infection<smiles>CO[C@@]1(C(F)(F)F)COC2(C)CCC3C(C)CCC(C)[C@]3(CC2)O1</smiles>

$\mathrm{CF}_{3}$-artemether (4) antimalarial agents

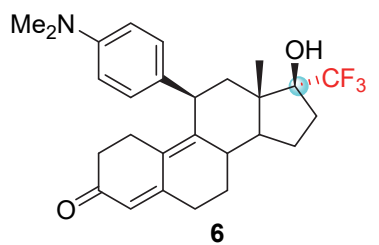

progesterone receptor antagonist

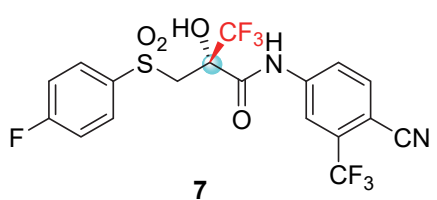

anticancer agent
图 1 含三氟甲基手性中心的生物活性分子

Figure 1 Selected biologically active molecules bearing a $\mathrm{CF}_{3}$ chiral center

三氟乙胺 $\left(\mathrm{CF}_{3} \mathrm{CH}_{2} \mathrm{NH}_{2}, 8\right)$ 作为含有三氟甲基的重要 合成砌块在合成领域的利用现已取得很大的进展 ${ }^{[3]}$, 但 是将其应用于不对称构建官能团化的 $\alpha$-三氟甲基胺类 化合物的研究就显得相对薄弱. 直到 2015 年, 王锐课题 组 ${ }^{[4]}$ 首次报道了三氟乙胺一吲哚酮亚胺衍生物 10 作为 1,3-偶极子成功应用于有机催化不对称 $[3+2]$ 环加成反 应之中. 随后, 在此基础上 Enders 课题组 ${ }^{[5]}$ 和王锐课题 组 ${ }^{[6]}$ 先后合成了三氟乙胺-丙二酸酯类酮亚胺 12 , 并发 展了相应不对称环加成反应(Scheme 1). 至此, 拉开了
三氟乙基酮亚胺在有机催化不对称合成研究中应用的 序幕, 经国内外各研究团队的努力, 在过去短短五年内, 发展许多高效的新型催化体系，拓展了该类型化合物在 有机合成中的应用范围. 为了总结该类型化合物的最新 研究进展，本综述将以三氟乙基酮亚胺的底物类型为主 线，对反应机理、反应的优点与局限及应用进行讨论， 并对该领域未来发展做出展望.

\section{1 三氟乙基吲哚酮亚胺的催化不对称环加成反 应}

\section{1 与直链共轭烯烃的不对称 $[3+2]$ 环加成反应}

2015 年, 王锐课题组 ${ }^{[4]}$ 首次利用稳定的三氟乙胺盐 酸盐 13 与吲哚酮 9 在对甲苯磺酸 14 催化下一步直接高 效地合成了三氟乙基吲哚酮亚胺 10 , 并利用手性二级 胺 C1 作为催化剂, 发展了一类 10 与 $\alpha, \beta$-不饱和醛 15 之间的不对称 $[3+2]$ 环加成反应, 简洁高效地构建含有 四个连续手性中心的螺环吲哚衍生物 16 (Scheme 2). 该 反应条件温和，对底物不同位置和电性的取代基具有良 好的兼容性. 同时, 作者基于产物的绝对构型推测出反 应的过渡态模型: 脯氨醇硅醚作为手性二级胺催化剂与 烯胺形成亚胺离子中间体，由于 $R e$-面芳基位阻的影响， 环加成反应则发生在三氟乙基酮亚胺的 $S i$-面.

同年，该课题组 ${ }^{[7]}$ 又探究了 $\beta$-硝基烯 17 作为 $2 \pi$ 体 系，与三氟乙基吲哚酮亚胺 $\mathbf{1 0}$ 之间的催化不对称 $[3+2]$ 环加成反应, 该方法通过手性叔胺-方酰胺双功能催化 剂 C2 对底物的双重活化与立体选择性控制, 以优异的 非对映选择性(all > 20：1 $d r$ ) 和对映选择性(94\% > 99\% ee)合成了一系列含有硝基、三氟甲基等多官能团化 的手性螺环吲哚衍生物 18 (Scheme 3). 该方法以简洁高 效的催化不对称策略，实现了连续四个手性中心的控制 和手性螺环的构建. 并且该催化反应具有广泛的底物普 适性，仅当吲哚酮骨架 4-位为氯原子时，反应无法进行.

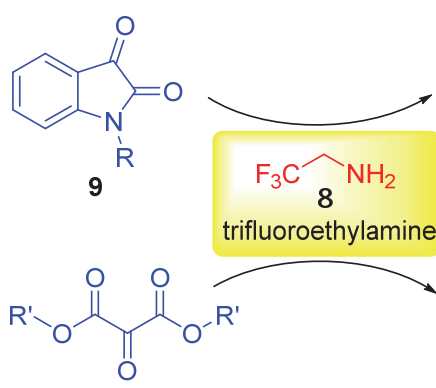

11<smiles></smiles>

trifluoroethyl ketimines
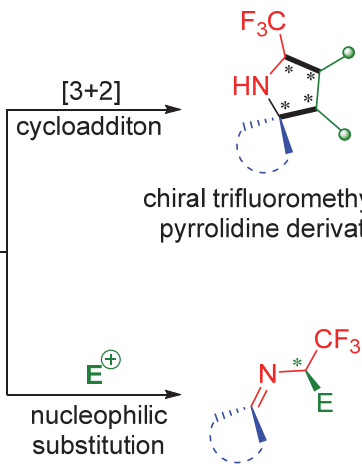

chiral trifluoromethylated pyrrolidine derivatives

chiral $\alpha$-trifluoromethylamines

图式 1 常见三氟乙基酮亚胺的类型及反应

Scheme 1 Types and reactions of common trifluoroethylketimines 

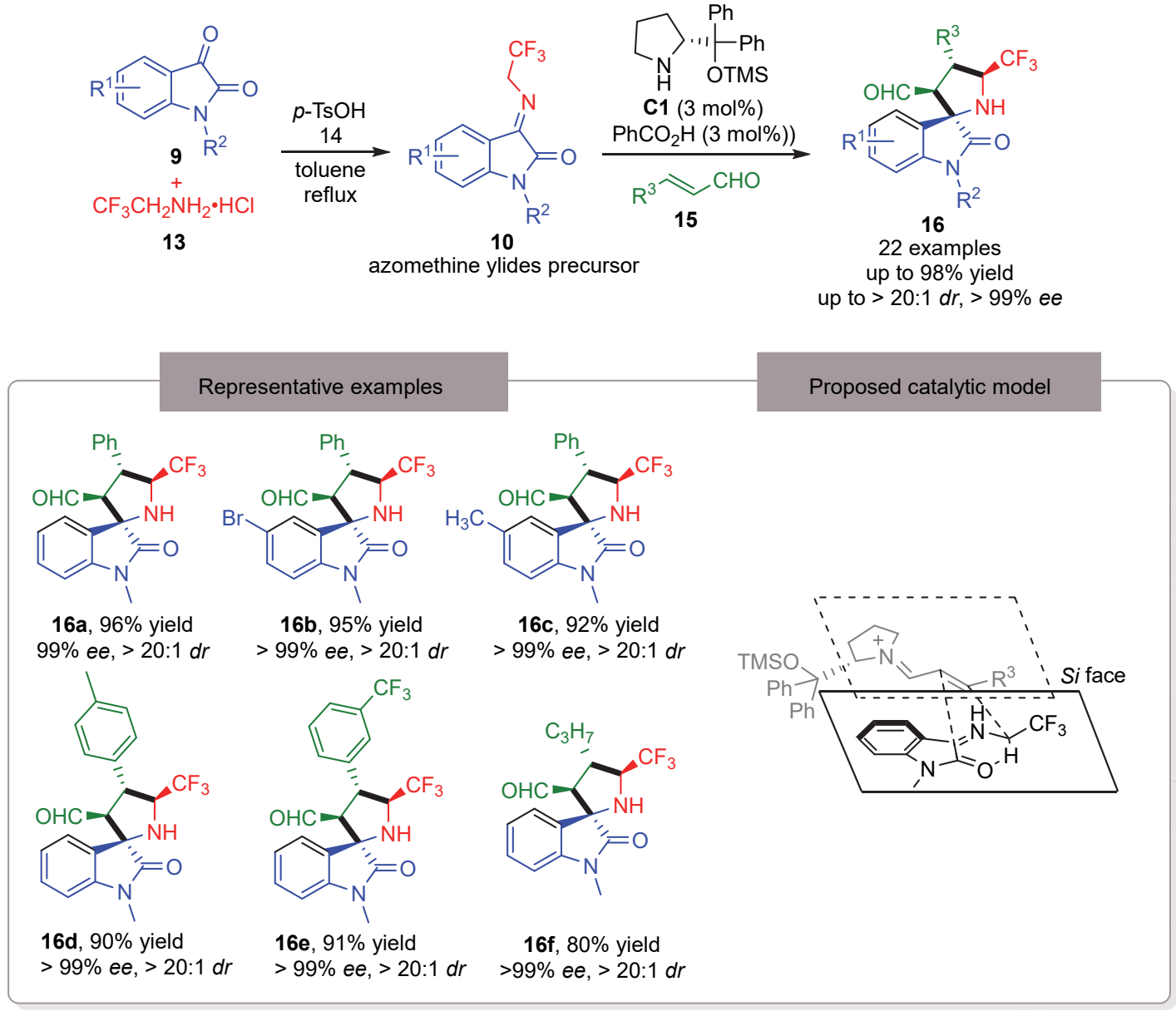

图式 2 催化三氟乙基吲哚酮亚胺与烯醛不对称 $[3+2]$ 环加成反应

Scheme 2 Catalytic asymmetric [3+2] cycloaddition of trifluoroethylisatin ketimines and enals

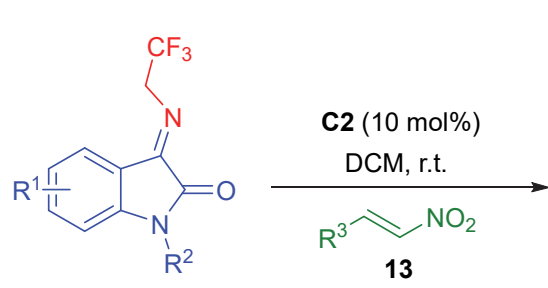

10

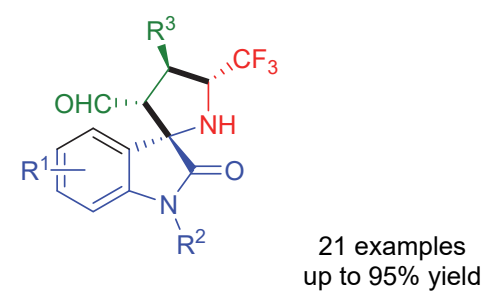
16 up to $>20: 1 d r, 98 \%$ ee

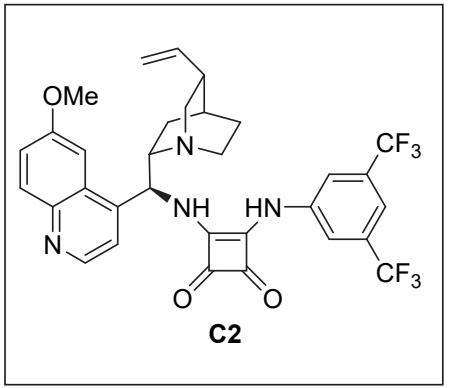

proposed transition state model

图式 3 有机催化硝基烯与三氟乙基吲哚酮亚胺不对称环加成反应

Scheme 3 Organocatalytic asymmetric cycloaddition of nitroalkenes with trifluoroethylisatin ketimines

2018 年, 袁伟成课题组 ${ }^{[8]}$ 成功实现了三氟乙基吲哚

酮亚胺 10 与 $\beta$-三氟甲基 $-\alpha, \beta$-烯酩 19 的不对称 $[3+2]$ 环 
加成反应(Scheme 4). 经过条件篮选, 确立了以奎宁衍 生的方酰胺 C2 为催化剂，二氯甲烷为溶剂， $5 \mathrm{~mol} \%$ 的 催化剂用量, $0{ }^{\circ} \mathrm{C}$ 下为该催化体系的最优条件. 在最优 条件下，该反应表现出对底物取代基的电子效应和空间 位阻良好的耐受性，顺利地以高达 $99 \%$ 的产率，>20： 1 的 $d r$ 值及 $>99 \%$ 的 $e e$ 值获得含双三氟甲基手性吡咯 烷螺环吲哚衍生物 20. 同时, 作者进行了克级规模实 验，产率和立体选择性均可保持, 表明了该方法具有良 好的实用性.

2019 年, 陈应春课题组 ${ }^{[9]}$ 利用手性脯氨醇硅醚催化
剂 C3 和 C4 通过多共轭亚胺离子最低空分子轨道 (LUMO)降低的策略实现了乙烯基取代芳香醛 21 的活 化，并发展了其与三氟乙基吲哚酮亚胺 10 的不对称环 加成反应(Scheme 5). 该反应条件温和且具有优异的底 物普适性，适用于含有不同电性、位置取代的酮亚胺底 物. 但是，对于乙烯基取代芳香醛而言，醛基和乙烯基 的位置对于反应活性和立体选择性有很大影响. 对于邻 乙烯基苯甲醛底物，须在 3-位引入 $\mathrm{NO}_{2}$ 才能使反应顺利 进行. 通过螺环吲哚产物 22 的绝对构型，作者提出相应 的反应机理: 手性二级胺催化醛 21 形成多共轭亚胺离<smiles>[R1]c1ccc2c(c1)N([R1])C(=[O+])/C2=N/CC(F)(F)F</smiles>

10<smiles>[R]C(=O)/C=C/C</smiles>

19 C2 $(5 \mathrm{~mol} \%)$ 25 examples up to $99 \%$ yield up to $99 \%$ ee, all > 20:1 $d r$

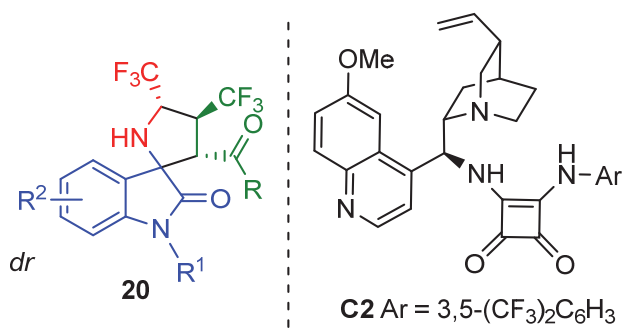

Representative examples<smiles>O=C(Oc1ccccc1)C1N(Cc2ccccc2)c2ccccc2C12C[C@@H](F)[C@@H](C(F)(F)F)N2</smiles>

20a $98 \%$ yield $>20: 1 d r, 98 \%$ ee

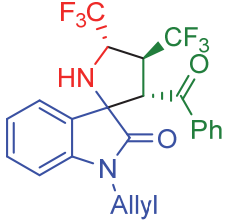

20b $86 \%$ yield $>20: 1 d r, 97 \%$ ee

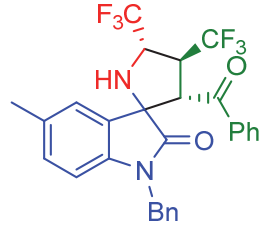

20c $99 \%$ yield $>20: 1 d r, 98 \%$ ee

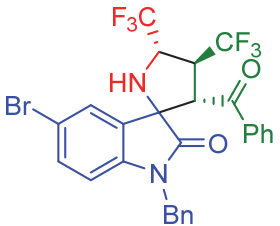

20d $99 \%$ yield $>20: 1 d r, 95 \%$ ee

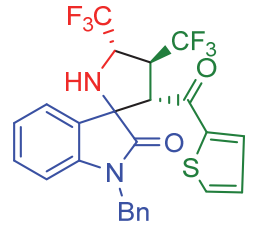

20 e $98 \%$ yield $>20: 1 d r, 98 \%$ ee

图式 4 三氟乙基吲哚酮亚胺与 $\beta$-三氟甲基烯酮的不对称环加成反应

Scheme 4 Asymmetric cycloaddition of trifluoroethylisatin ketimines and $\beta$-trifluoromethylenones

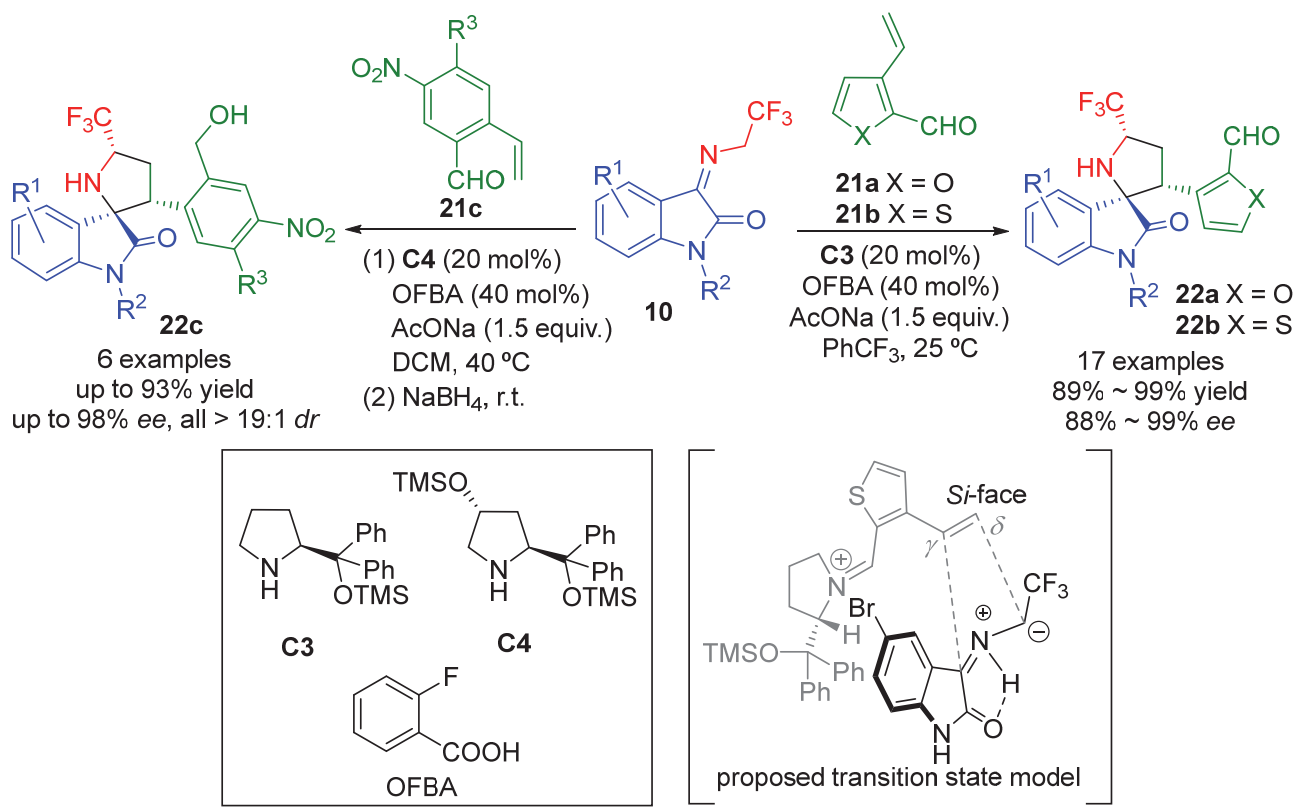

图式 5 乙烯基取代芳醛与三氟乙基吲哚酮亚胺不对称环加成反应

Scheme 5 Asymmetric cycloaddition of trifluoroethylisatin ketimines with vinyl substituted aryl aldehydes 
子活化 $\gamma, \delta$-位 $\pi$ 体系, 进而与酮亚胺 $\mathbf{1 0}$ 发生环加成反应 并完成立体选择性的控制.

最近, 叶金星课题组 ${ }^{100}$ 报道了利用手性伯胺 C5 作 为催化剂, 催化环状 2,4-二烯酮 23 与三氟乙基酮亚胺 10 之间的远程区域选择性的不对称 [3+2]环加成反应 (Scheme 6), 以最高 94\%的产率和最高 $95 \%$ ee、 $>19: 1$ $d r$ 值获得一系列手性四氢吡咯烷螺环吲哚衍生物 24. 该方法可实现多个新的碳一碳键简洁高效的构建, 也可 应用于合成含有手性环己烯酮结构单元的复杂螺环化 合物.<smiles>O=C1Nc2ccccc2/C1=N/CC(F)(F)F</smiles>

$10^{R^{2}}$

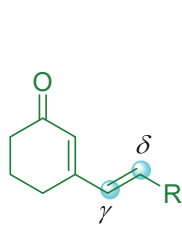

23

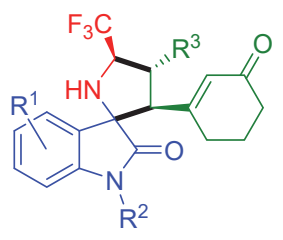

24

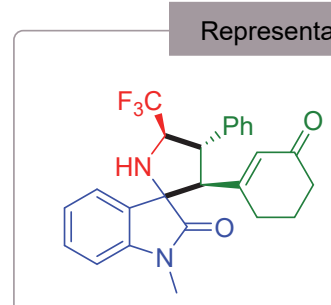

24a, $83 \%$ yield $90 \%$ ee, $15: 1 d r$

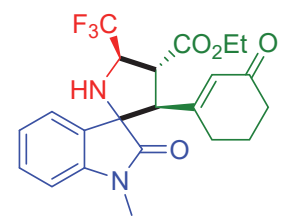

24c, $83 \%$ yield $94 \%$ ee, $7: 1 d r$

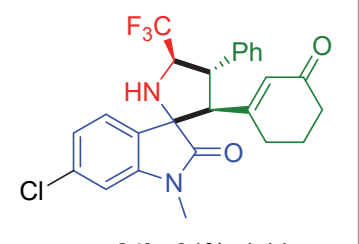

24b, $84 \%$ yield

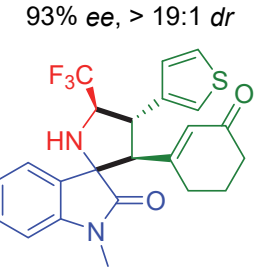

24d, 76\% yield $90 \%$ ee, $10: 1 d r$
图式 6 环状 2,4-二烯酮与三氟乙基吲哚酮亚胺的远程区域选 择性的不对称环加成反应

Scheme 6 Remote regioselective asymmetric cycloaddition of trifluoroethylisatin ketimines with cyclic 2,4-dienones

\section{2 与单杂环外烯烃的不对称 $[3+2]$ 环加成反应}

由于环外烯烃的碳一碳双键与缺电子烯烃具有相似 的化学活性, 被认为是构建手性螺环骨架的行之有效的 合成子, 因此, 备受合成及药物化学家的关注, 并迅速 成为有机合成领域的研究热点之一. 通过多个课题组研
究人员的不解努力, 近年来该领域的研究成果颇丰. 研 究表明, 环外烯烃在金鸡纳碱衍生的方酰胺或双功能硫 䐖活化下可与三氟乙基吲哚酮亚胺构建类型丰富、结构 复杂的新型手性螺环衍生物, 本节将根据环外烯烃的类 型对这部分的研究工作进行详细介绍.

含有丁烯酸内酯骨架的 3-烯基-5-芳基呋喃 2(3H)酮 25 是一类重要的合成子, 在有机及药物合成化学中 应用广 ${ }^{[11]}$. 2016年，袁伟成等 ${ }^{[12]}$ 利用 25 作为缺电子烯烃 试剂，实现了在低催化剂负载量 $(\mathbf{C 5}, 1 \mathrm{~mol} \%)$ 条件下其 与三氟乙基吲哚酮亚胺 10 的不对称 $[3+2]$ 环加成反应 (Scheme 7). 该方法高效、高立体选择性地合成了含有 三氟甲基且具有四个连续手性中心(包括两个相邻手性 螺季碳中心)的复杂吡咯烷双螺环吲哚化合物 26. 作者 通过克级反应和进一步的化学转化证实了所发展方法 的潜在实用性，为复杂螺环骨架的不对称构建提供了全 新策略. 同时, 基于实验数据和产物的绝对构型, 提出 了反应的过渡态模型，进一步阐释了该反应是通过叔 胺-硫脲催化的双功能活化模式实现底物活化以及立体 选择性控制.

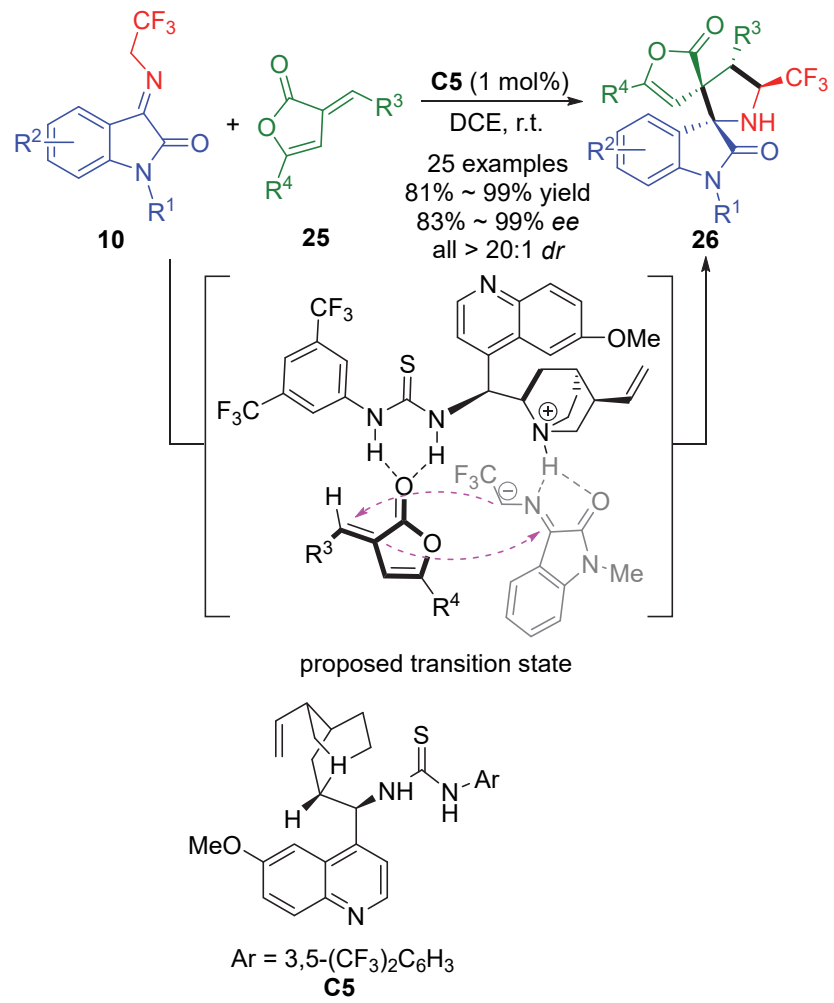

图示 7 三氟乙基吲哚酮亚胺与 3-烯基-5-芳基呋喃 2(3H)-酮 的不对称 $[3+2]$ 环加成反应

Scheme 7 Asymmetric [3+2] cycloaddition of 3-alkenyl-5arylfuran-2(3H)-ones with trifluoroethylisatin ketimines

2018 年, 杜大明课题组 ${ }^{[13 a]}$ 发展了一类金鸡纳碱双 功能催化剂 C6 催化的罗丹明衍生环外烯烃 27 与三氟乙 
基吲哚酩亚胺 10 之间的高非对映选择性(up to $99: 1$ $d r$ ) 和对映选择性(up to $99 \%$ ee) 的 Michael/Mannich 串联 $[3+2]$ 环加成反应. 2019 年, 该课题组先后利用相同的 催化策略实现了亚芳基唤酯 $\mathbf{2 8}^{[13 \mathrm{~b}]}$ 和巴比妥酸衍生烯 烃 29 ${ }^{[13 c]}$ 与三氟乙基吲哚酮亚胺 10 之间的不对称环加成 反应(Scheme 8). 该催化策略条件温和, 均可在最优催 化条件下顺利地实现结构复杂的含 $\mathrm{CF}_{3}$ 的双螺环吲哚-
吡咯烷衍生物 30 的对映选择性合成，拓展了化学生物 学和药物研发中候选药物分子的多样性与选择性.

问文锦和王凯荣等继续拓展了环外双键体系与三 氟乙基吲哚酮亚胺的不对称环加成反应的研究. 发展了 有机催化的橙酮 31 ${ }^{[14 \mathrm{a}]}$ 和 $\alpha, \beta$-不饱和吡唑啉酮 32 ${ }^{[14 b]}$ 与三 氟乙基吲哚酮亚胺 10 的不对称 $[3+2]$ 环加成反应 (Scheme 9). 实现了在温和的条件下简洁高效地合成

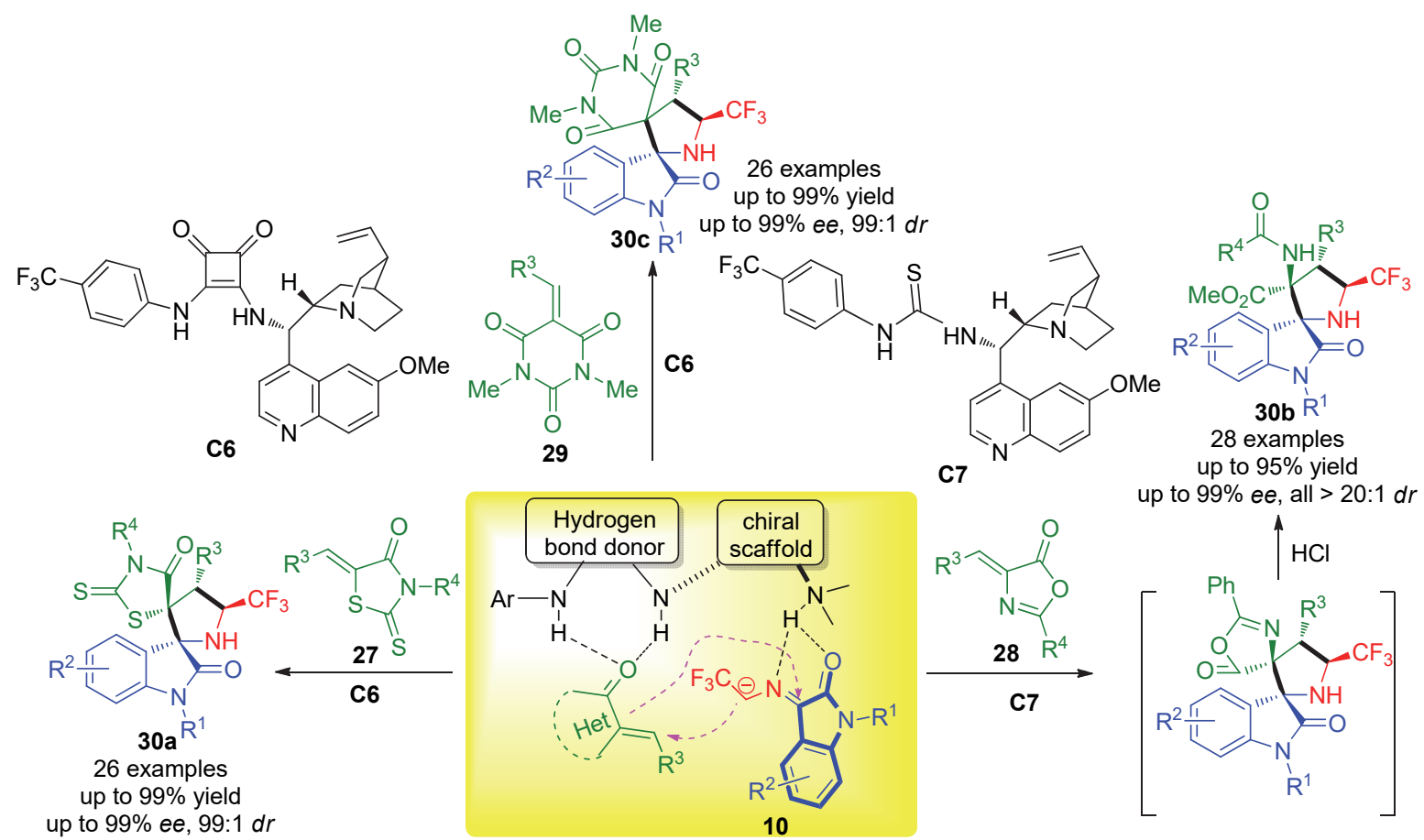

图式 8 杜大明课题组关于环外烯烃与三氟乙基吲哚酮亚胺不对称环加成反应的研究

Scheme 8 Asymmetric cycloaddition of exocyclic olefins with trifluoroethylisatin ketimines by Du's group

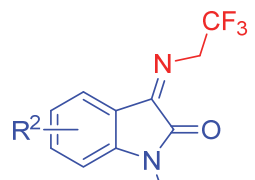

$10 \mathrm{R}^{1}$

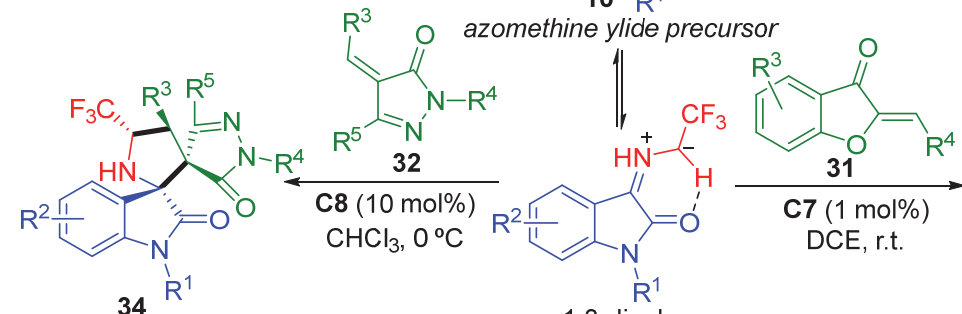

$34 \mathrm{R}^{1}$

36 examples up to $91 \%$ yield, $99 \%$ ee all $>20: 1 d r$ 1,3-dipole

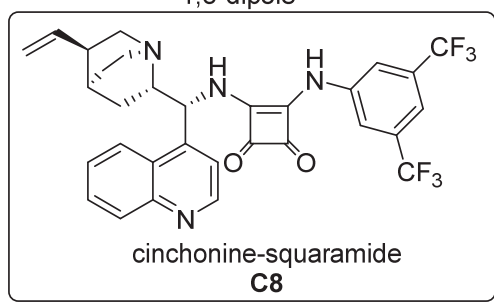

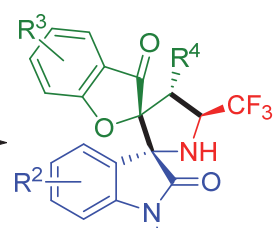

$33 \mathrm{R}^{1}$

30 examples $73 \% \sim 99 \%$ yield $86 \% \sim 99 \%$ ee, all $>20: 1 d r$

图式 9 有机催化橙酮和 $\alpha, \beta$-不饱和吡唑啉酮与吲哚酮亚胺的不对称环加成反应

Scheme 9 Organocatalytic asymmetric cycloaddition between isatinketimines and aurones \& $\alpha, \beta$-unsaturated pyrazolones 
具有优异立体选择性的新型含有苯并呋喃和吡唑啉䣶 骨架的双螺环吲哚化合物 33 和 34.

2019 年, 蒋先兴课题组 ${ }^{[15]}$ 将 2,3-二羰基吡咯烷 35 成功应用到非对映选择性发散的不对称 $[3+2]$ 环加成反 应之中(Scheme 10). 在最优条件下, 所有反应均可顺利 进行并以最高 96\%的产率和最高 $99 \% e e$ 值的对映选择 性得到系列具有两个相邻季碳中心的手性螺双吡咯烷 衍生物 36. 值得注意的是, 该方法在单一催化条件下, 可通过控制反应时间分别获得单一构型非对映异构体. 作者通过控制实验深入地研究了非对映选择性转换的 机理：方酰胺 C9 通过双活化模式活化吡咯烷 35 和吲哚 酮亚胺 10 并控制 $\operatorname{Michael}(S i$-attact)/Mannich(Re-attact) 串联反应(TS-1)的立体选择性获得化合物 36b, 同时也 可通过 $\operatorname{Michael}(S i$-attact)/Mannich(Si-attact) 串联反应 (TS-2) 获得等量非对映体 36a (Path A). 若延长反应时 间, 36b 中相邻螺季碳之间的碳碳键在酸性条件下断键,
并发生分子内 Mannich 反应 $(S i$-attact)转化为 36a (TS-3, Path B).

最近，王天利课题组 ${ }^{[16]}$ 基于手性二肽发展了一类 手性双功能季磷盐相转移催化剂 $\mathbf{C 1 0}$, 并成功将其应用 于三氟乙基吲哚酮亚胺 10 与 2,3-二羰基吡咯烷 35 的不 对称 1,3-偶极环加成反应中. 该方法对各类型底物具有 良好的耐受性, 均可高效地获得光学纯的环加成产物 36a (Scheme 11). 同时，作者通过控制实验证实了手性 季磷盐是通过离子对/氢键效应的协同作用对底物进行 活化以及立体选择性控制.

\section{3 与 3-甲烯基吲哚酮类化合物的不对称 $[3+2]$ 环加 成反应}

3-甲烯基吲哚酮 37 结构中含有活性碳碳双键，作 为 $2 \pi$ 给体被广泛应用于催化不对称合成, 尤其是不对 称环加成反应中 ${ }^{[17]}$, 是构建手性螺环吲哚衍生物的优 良有机合成子，因此，引起国内外多个研究组的关注并
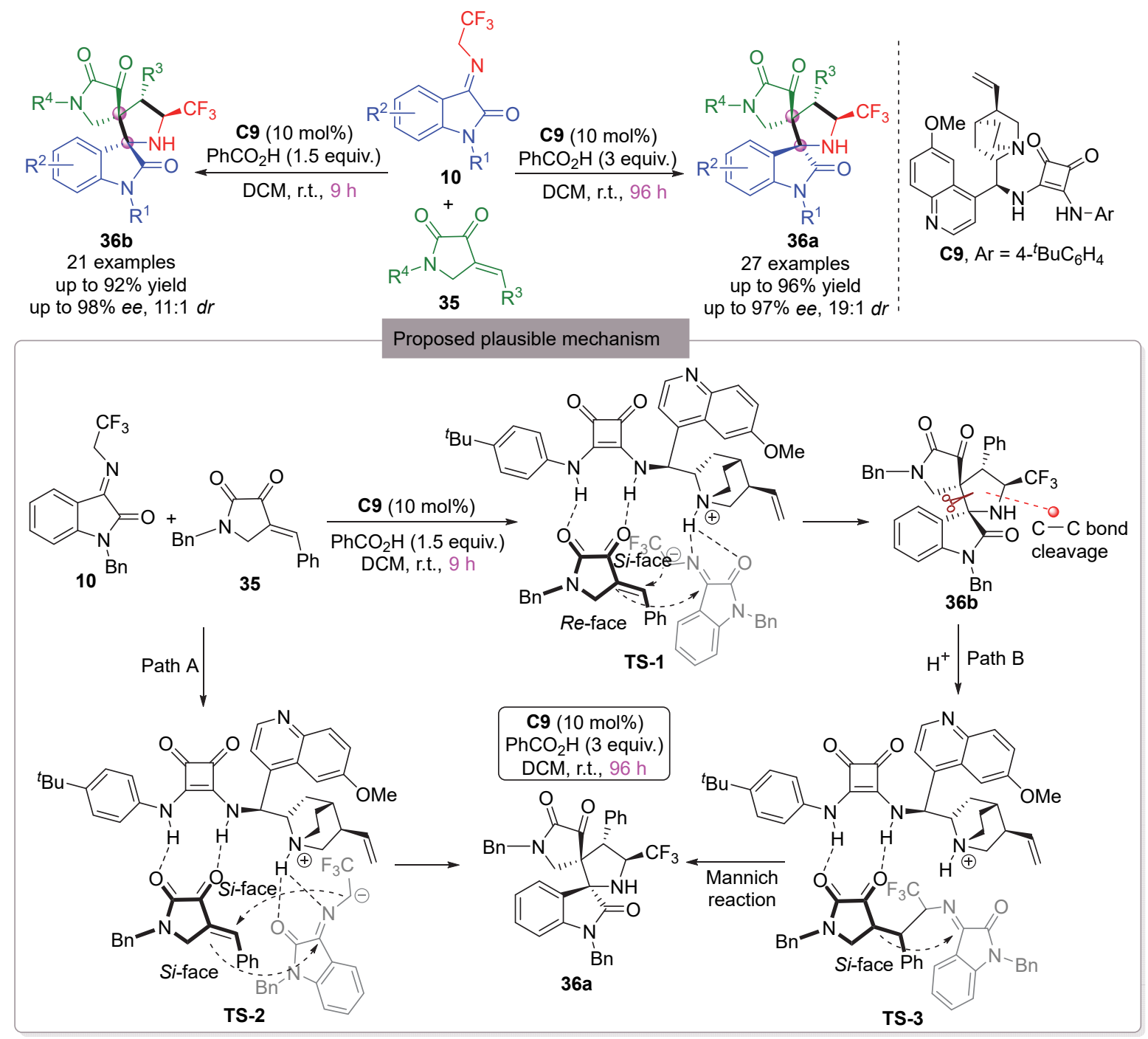

图式 10 2,3-二羊基吡咯烷非对映选择性发散的不对称[3+2]环加成反应

Scheme 10 Diastereodivergent asymmetric [3+2] cycloaddition of 2,3-dioxopyrrolidines 


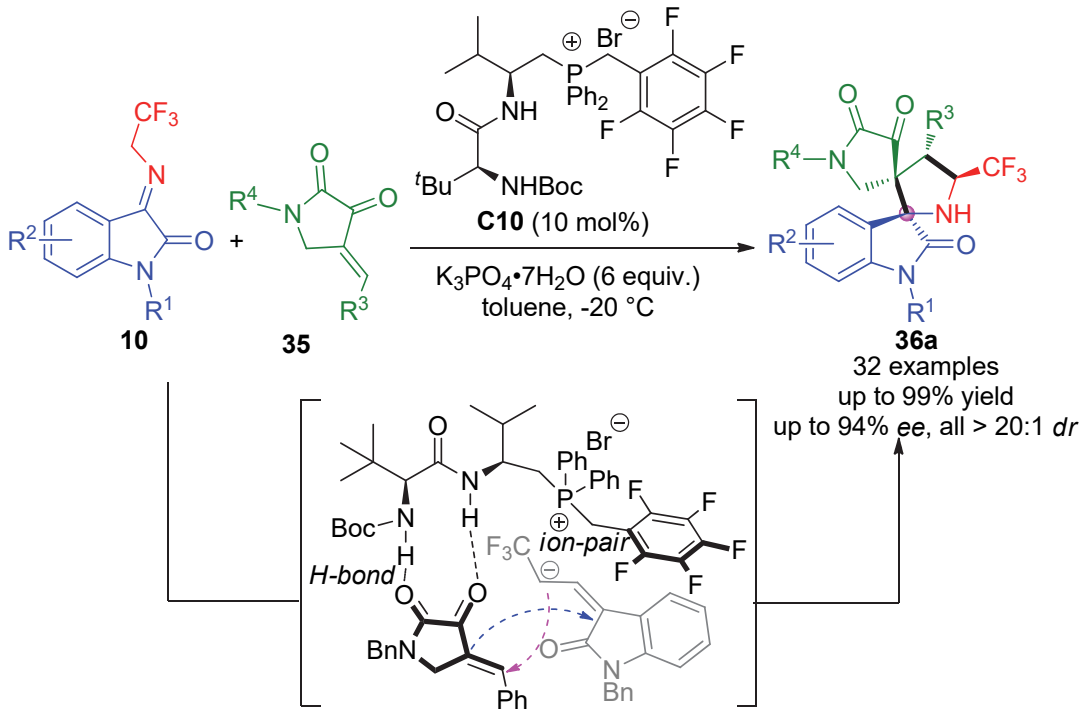

图式 11 手性双功能季磷盐催化的不对称 1,3-偶极环加成反应

Scheme 11 Asymmetric 1,3-dipolar cycloaddition via chiral bifunctionalphosphonium salt

将其作为重点研究内容. 2017 年以来, 鲁桂课题组 ${ }^{[18 \mathrm{a}]}$ 、 Enders 课题组 ${ }^{[18 b]}$ 、杜大明课题组 ${ }^{[18 c]}$ 和王敏灿课题组 ${ }^{[18 d]}$ 先后将 $\mathbf{3 7}$ 成功地引入到与三氟乙基吲哚酮亚胺 $\mathbf{1 0}$ 的有 机催化不对称 $[3+2]$ 环加成反应中(Scheme 12). 高效、 高立体选择性地合成了一系列具有潜在生物活性的含 有三氟甲基的 3,3-吡咯烷-双螺环吲哚酮衍生物 38, 为
拓展构建复杂手性吡咯烷一双螺环吲哚骨架提供了新方 法, 也为发现具有较好生理活性的新型杂环化合物奠定 基础.

袁伟成课题 ${ }^{[8]}$ 和鲁桂课题组 ${ }^{[19]}$ 继续深入研究，相继 报道了 3-三氟亚乙基吲哚酮 39 与吲哚酮亚胺 10 之间的 不对称环加成反应(Scheme 13), 两种方法均采用方酰<smiles>COC1=CC2=C3C=CN=C(C=C1)C(CC2)C3NC1C(=O)C(=O)C1CCN1C2CCC1CC2</smiles>

C14

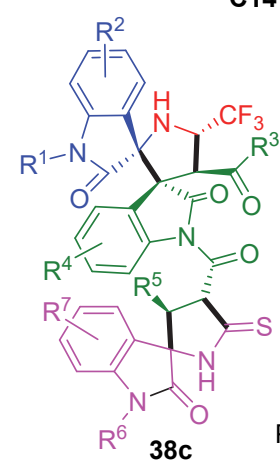

31 examples $81 \% \sim 95 \%$ yield $97 \% \sim 99 \%$ ee $8: 1>20: 1 d r$

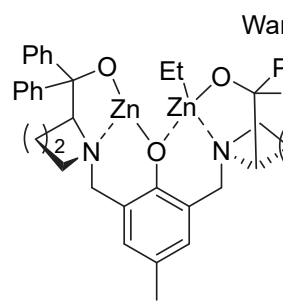

C13

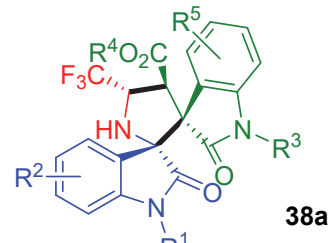

$\mathrm{R}^{1} \quad 23$ examples

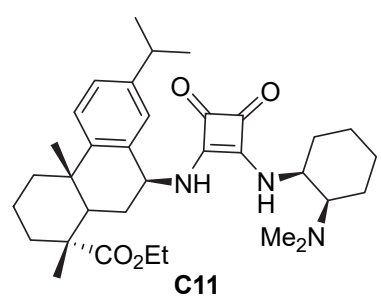
Lu' group C11 $62 \% \sim>99 \%$ ee

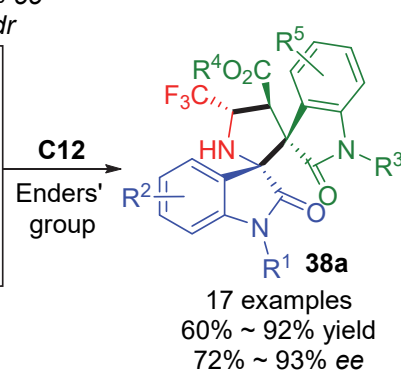

图式 12 吲哚酮亚胺与 3-甲烯基吲哚酮催化不对称环加成反应

Scheme 12 Catalytic asymmetric cycloaddition of isatin-based ketamines with 3-metheneindolinones 


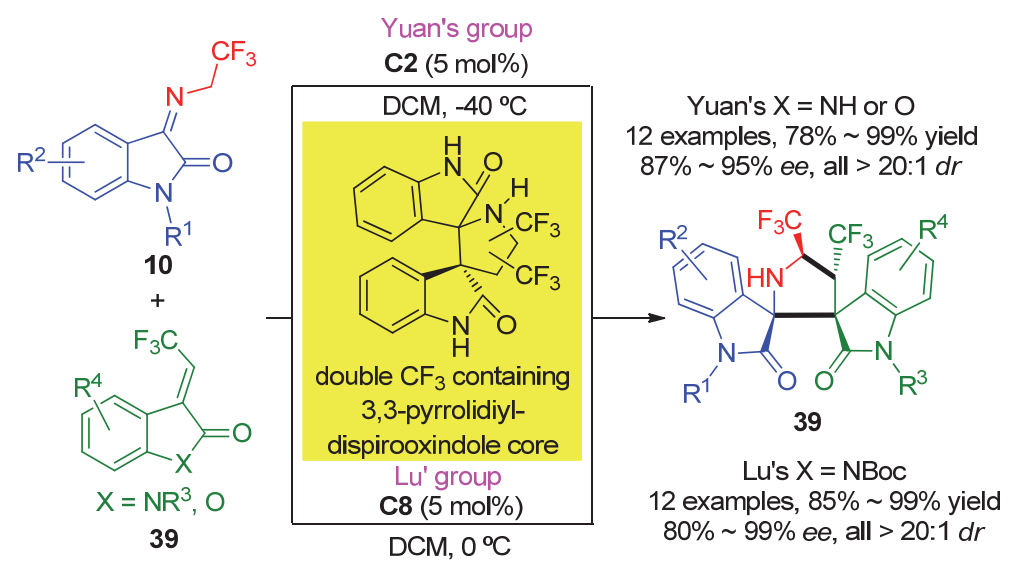<smiles>C=CC1CC2CC1N1CC2CC1Nc1c(Nc2cc(C(F)(F)F)cc(C(F)(F)F)c2)c(=O)c1=O</smiles>

图式 13 有机催化 3-三氟亚乙基吲哚酮与吲哚酮亚胺之间的不对称环加成反应

Scheme 13 Organocatalytic asymmetric cycloaddition of isatin-based ketamines with 3-trifluoroethylideneoxindoles

胺类催化剂, 并均可顺利地合成含有两个三氟甲基的手 性吡咯烷-双螺环吲哚酮衍生物 40. 突显了这些研究工 作(Schemes 12, 13)在一步构建光学纯的复杂螺环骨架 的重要作用.

\section{2 三氟乙基吲哚酮亚胺作为亲核试剂的催化不 对称反应}

三氟乙基吲哚酮亚胺除了作为甲亚胺叶立德广泛 参与到 1,3-偶极环加成反应中, 近来研究表明其也可作 为单一的亲核试剂充当合成手性 $\alpha$-三氟甲基胺衍生物 的合成砌块. 2016 年, 王锐等 ${ }^{[20]}$ 报道了 $\beta$-6'-羟基异辛可
宁 C15 作为有机催化剂, 催化的 Morita-BaylisHillman 酯(MBH 酯) 40 与 10 的催化不对称 $\mathrm{S}_{\mathrm{N}} 2^{\prime}-\mathrm{S}_{\mathrm{N}} 2^{\prime}$ 反 应(Scheme 14), 高效地合成了系列具有光学活性的 $\alpha$ 三氟甲基胺类化合物 41. 该方法条件温和，普适性广 泛, 并且 41 在浓盐酸条件下即可构建抗癌药物中常见 的手性 $\alpha$-三氟甲基丁内酰胺骨架 42 .

王春江课题组 ${ }^{[21]}$ 在 2019 年首次报道了三氟乙基吲 哚酮亚胺具有极性反转的特性, 并发展了手性铱催化 10 与苯丙烯基碳酸甲酯 43 之间的极性反转的烯丙基化/ 2-氮杂-Cope 重排的串联反应(Scheme 15), 该方法为对 映选择性获得含有 $\alpha$-三氟甲基的高烯丙基胺化合物 44<smiles>[R][X]c1ccc2c(c1)N(C)C(=O)/C2=N/CC(F)(F)F</smiles>

10<smiles>[R3]C(=O)C(=C)C([R])OC(=O)OCC</smiles>

40

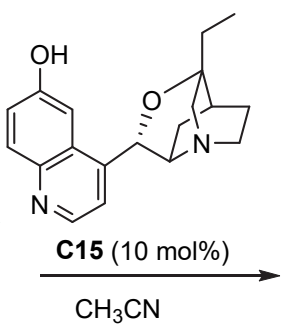

$\mathrm{CH}_{3} \mathrm{CN}$

\section{Representative examples}

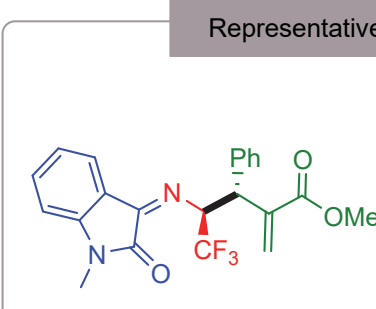

41a, $91 \%$ yield $>20: 1 d r, 91 \%$ ee<smiles>C=C(C(=O)OC)[C@H](c1ccccc1)[C@H](N=C1C(=O)N(C)c2cccc(Br)c21)C(F)(F)F</smiles>

41b, $80 \%$ yield $>20: 1 d r, 91 \%$ ee<smiles>C=C(C(=O)OC)[C@H](c1ccc(C)cc1)[C@H](N=C1C(=O)N(C)c2cccc(Cl)c21)C(F)(F)F</smiles>

41c, $88 \%$ yield $>20: 1 d r, 98 \%$ ee

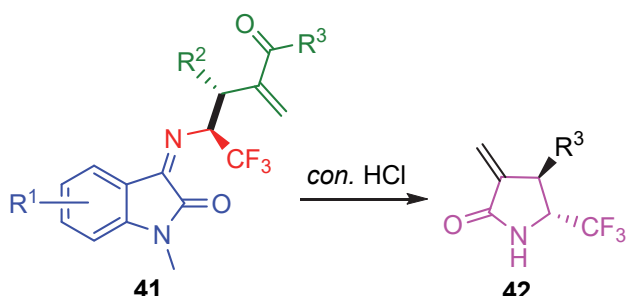

41

24 examples

up to $93 \%$ yield

up to $98 \%$ ee, $>20: 1 d r$

图式 $14 \mathrm{MBH}$ 型碳酸酯与吲哚酮亚胺之间的催化不对称 $\mathrm{S}_{\mathrm{N}} 2^{\prime}-\mathrm{S}_{\mathrm{N}} 2^{\prime}$ 反应

Scheme 14 Catalyzed asymmetric $\mathrm{S}_{\mathrm{N}} 2^{\prime}-\mathrm{S}_{\mathrm{N}} 2$ ' reaction between $\mathrm{MBH}$ type carbonates and isatin-based ketamines 

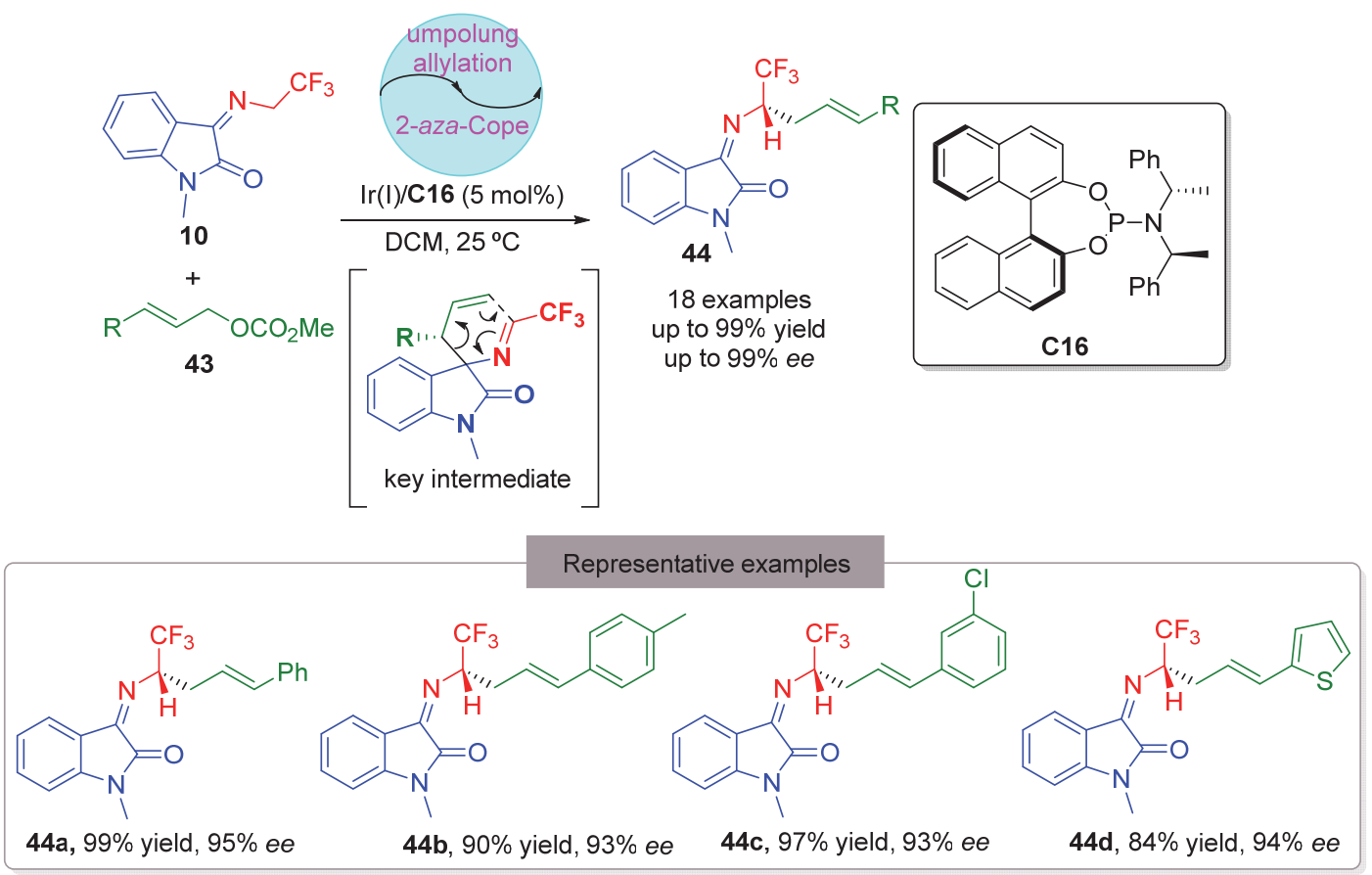

图式 15 三氟乙基吲哚酮亚胺的催化不对称极性反转烯丙基化/2-氮杂-Cope 重排串联反应

Scheme 15 Catalytic asymmetric cascade umpolung allylation/2-aza-Cope rearrangement reactions of isatin-based ketamines

提供高效、简洁的合成策略. 值得注意的是, 作者通过 ${ }^{19} \mathrm{~F} \mathrm{NMR}$ 、控制实验及 $\mathrm{X}$ 单晶衍射多种途径对反应机理 进行了深入细致的研究, 揭示了极性反转烯丙基化反应 中的关键中间体和 2-氮杂-Cope 重排反应中的立体中心 转移过程, 为后续相关反应的研究和应用奠定了扎实的 理论基础.

不久之后, Malcolmson 课题组 ${ }^{[22]}$ 发展了一类钯催化 吲哚酮亚胺 10 与末端二烯 45 之间的高区域选择性不对 称加氢烷基化反应(Scheme 16). 该方法首次利用内烯 烃高效、高立体选择性地合成 $\alpha$-三氟甲基的高烯丙基胺 类衍生物 44, 进一步拓展了手性高烯丙基胺的合成方 法.

最近, 鲁桂课题组 ${ }^{[23]}$ 报道了三氟乙基吲哚酮亚胺 10 在手性方酰胺双功能催化剂 C6 催化下通过极性反转 策略与环状酮亚胺 46 发生交叉 Mannich 反应(Scheme 17 ), 该反应在最优催化条件下，可以最高 $98 \%$ 的产率、 最高 $>20 ： 1 d r$ 值和 $>99 \%$ ee 值合成含有相邻手性季 碳的二胺衍生物 47. 该方法具有底物范围广泛、适用于 克级制备以及化学/区域选择性优秀等特点, 为其在生 物活性评价研究等实际应用提供先决条件. 同时也进一 步拓展了利用极性反转的策略合成手性胺类化合物的 方法.

近年来，基于芴基衍生的酮亚胺应用于催化不对称 构建手性胺的相关研究工作陆续见诸报道 ${ }^{[24]} .2019$ 年, 钮大文课题组 ${ }^{[25 a]}$ 和王春江课题组 ${ }^{[25 b]}$ 相继报道了手性
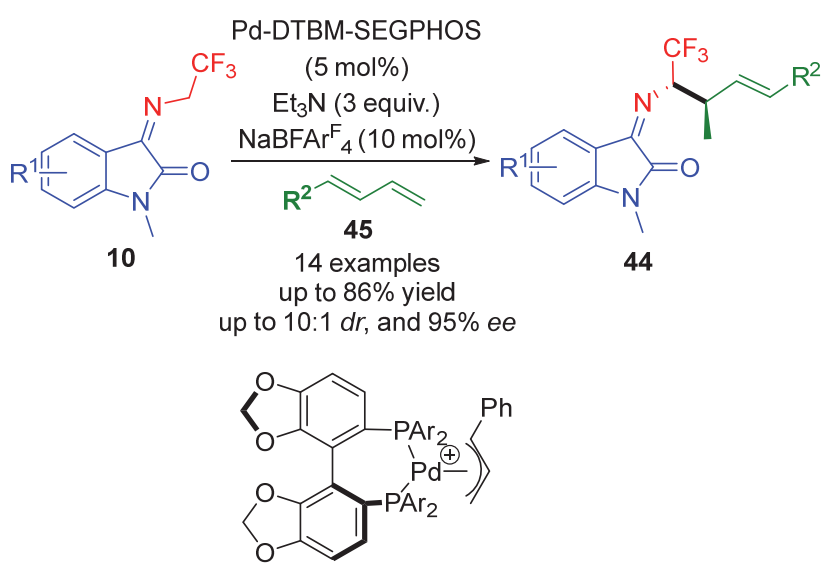

$\mathrm{Ar}=3,5-(t-\mathrm{Bu})_{2}-4-\mathrm{MeOC}_{6} \mathrm{H}_{2}$

Pd-DTBM-SEGPHOS

图式 16 末端二烯与吲哚酮亚胺的催化不对称加氢烷基化反 应

Scheme 16 Catalytic asymmetric hydroalkylation of terminadiene with isatin-based ketamines

铱催化芴衍生三氟乙基酮亚胺 48 与丙烯基碳酸酯 43 之 间的极性反转的烯丙基化/2-氮杂-Cope 重排的串联反应 (Scheme 18). 两个课题组所发展的方法均具有广泛的 底物普适性, 且均可以优秀的产率和对映选择性合成 $\alpha$ 三取代 $\alpha$-三氟甲基的高烯丙基胺化合物 44, 为进一步 拓展多取代手性高烯丙基胺的合成方法奠定了坚实基 础. 
<smiles>[R1]c1ccc2c(c1)C(=NCC(F)(F)F)N([R])C2=O</smiles><smiles>[R]OC(=O)c1c(N([R])C(C)(C)C)c2cc[Y10](F)cc2n1C(=O)O</smiles>
$46 \quad \mathrm{R}^{3} \quad$ up to $98 \%$ yield up to $>20: 1 d r,>99 \%$ ee

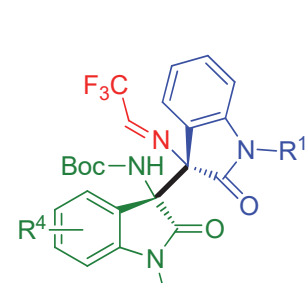

$\mathrm{R}^{3} 47$

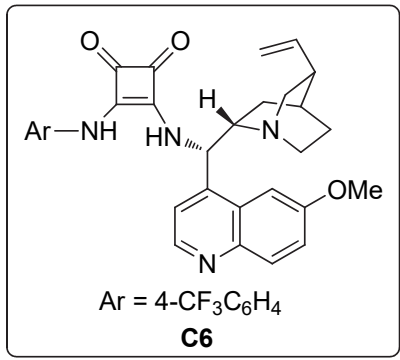

\section{Representative examples}

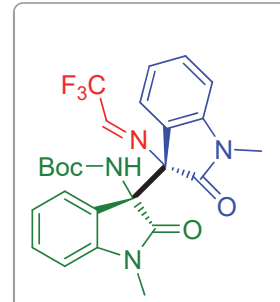

47a, $93 \%$ yield $>20: 1 d r, 95 \%$ ee

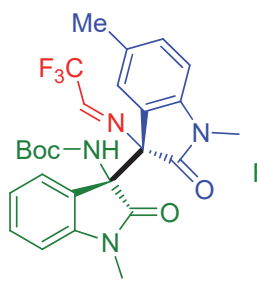

47b, $94 \%$ yield $>20: 1 d r, 98 \%$ ee

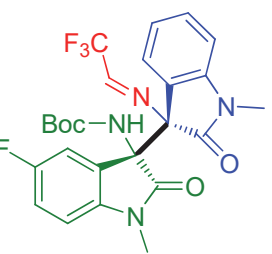

47c, $92 \%$ yield $>20: 1 d r, 94 \%$ ee

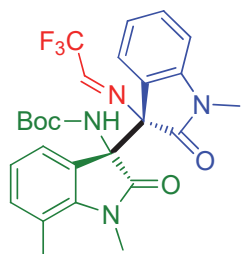

47d, $90 \%$ yield $>20: 1 d r, 96 \%$ ee

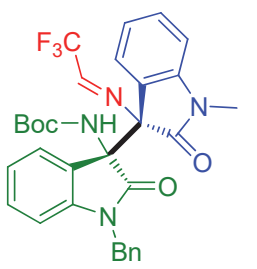

47e, $87 \%$ yield $>20: 1 d r,>99 \%$ ee

图式 17 催化三氟乙基吲哚酮亚胺的不对称极性反转交叉 Mannich 反应

Scheme 17 Catalytic asymmetric umpolung cross-Mannich reaction of trifluoroethylisatin ketimines

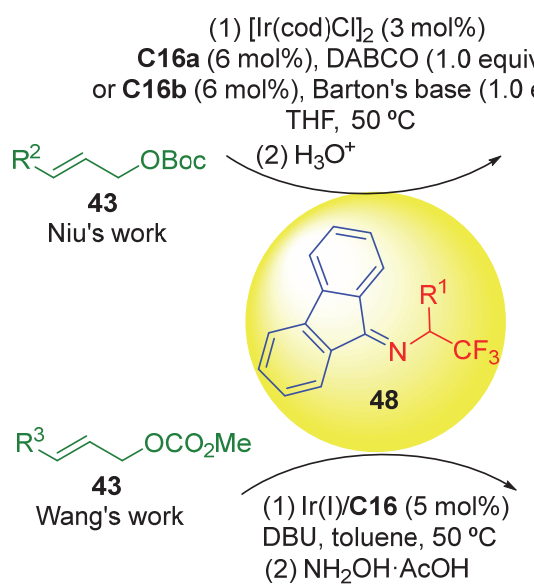 equiv.) $\mathrm{NH}_{2}$ $\mathrm{F}_{3} \mathrm{C}_{\mathrm{R}^{1}} \leadsto \mathrm{R}^{2}$ (S) -44 33 examples up to $98 \%$ yield up to $99 \%$ ee

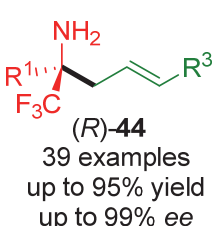<smiles>COc1ccccc1CN(C(C)c1ccccc1OC)P(Oc1ccc2ccccc2c1)c1c(O)ccc2ccccc12</smiles>

C16a<smiles>CC1CCc2ccccc2N1P(Oc1ccc2ccccc2c1-c1ccc2ccccc2c1)OC(C)(C)C</smiles><smiles>CC(c1ccccc1)N([C@H](C)c1ccccc1)P(Oc1ccccc1)Oc1ccc2ccccc2c1-c1ccccc1</smiles><smiles>CCCCCN=C(N(C)C)N(C)C</smiles>

Barton's base

图式 18 手性铱催化三氟乙基吲哚酮亚胺的不对称极性反转烯丙基化/2-氮杂-Cope 重排串联反应

Scheme 18 Chiral iridium catalyzed asymmetric cascade umpolung allylation/2-aza-Cope rearrangement reactions of isatin-based ketamines

张霞、蓝宇和刘捷等 ${ }^{[26]}$ 利用芴衍生三氟乙基酮亚胺 48 发展了一类区域选择性和对映选择性钯催化不对称 烯丙基化反应(Scheme 19). 此方法可广泛高效地合成 具有相邻手性中心的三氟乙胺化合物 $\mathbf{5 0}$, 并经简单合 成转化即可获得类型丰富的手性杂环骨架, 展示了该方 法良好的应用前景. 更为重要的是, 该催化体系可通过 手性配体 ${ }^{t} \mathrm{Bu}-\mathrm{PHOX} \mathrm{C17}$ 构型的改变控制反应的区域选 择性和产物的绝对构型, 作者通过控制实验和密度泛函 理论(DFT)计算对反应机理进行了深入的阐释.

\section{3 丙二酸酯衍生的三氟乙基酮亚胺的催化不对}

\section{称反应}

由于三氟乙基吲哚酮亚胺在环加成等反应的广泛
应用，促使研究人员持续对高活性三氟乙胺衍生的酮亚 胺的开发与研究探索. 2016 年王锐等 ${ }^{[27]}$ 首次利用酮基丙 二酸二乙酯发展了一类新型三氟乙基酮亚胺 12, 并将 其成功应用于有机催化不对称环加成反应中. 在手性方 酰胺 C18 催化下, 12 与 3-甲烯基吲哚酮 37 可顺利地发 生不对称 $[3+2]$ 环加成反应，以最高 $96 \%$ 的产率、最高 $>20: 1 d r$ 值和 $>99 \% e e$ 值获得一系列手性吡咯烷螺 环吲哚酮类化合物 51 (Scheme 20). 作者也通过目标产 物的绝对构型提出相应的反应机理: 手性方酰胺作为双 功能催化剂对三氟乙基酮亚胺 12 进行极性反转催化和 控制反应的立体选择性.

随后, Enders 课题组 ${ }^{[5]}$ 和王锐课题组 ${ }^{[6]}$ 先后报道了 手性脯氨酸硅醚 $\mathbf{C} 1$ 催化三氟乙基酮亚胺 12 与 $\alpha, \beta$-不 

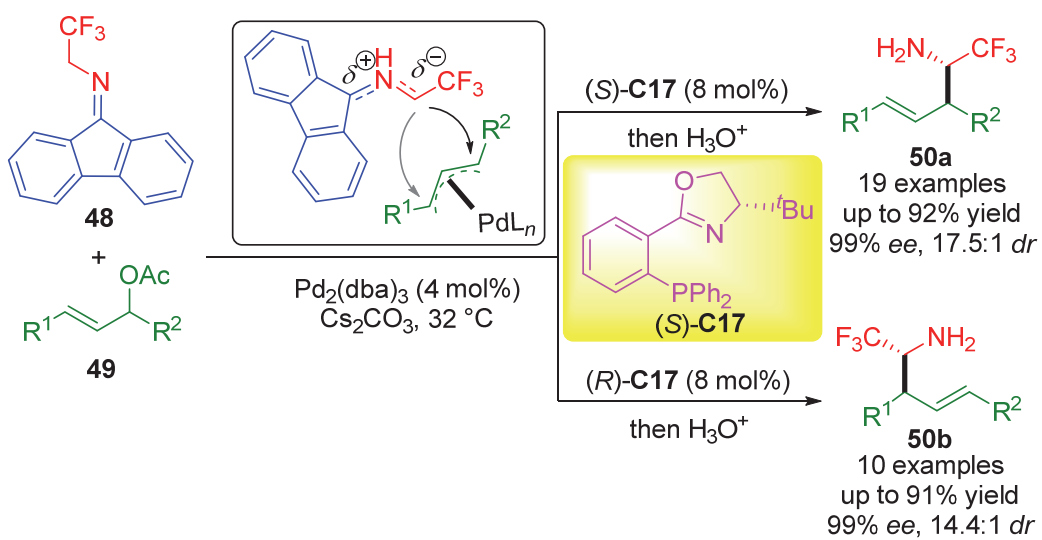

图式 19 钯催化三氟乙基芴基酮亚胺的不对称烯丙基化反应

Scheme 19 Palladium-catalyzed asymmetric allylation of trifluoroethylfluorene ketimines<smiles>[R]C=C1C(=O)N([R1])c2cc[R]#[13cH]c21</smiles>

37<smiles>CCOC(=O)C(=NCC(F)(F)F)OCC</smiles>

12

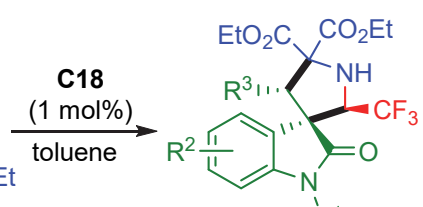

$51 \mathrm{R}^{1}$

20 examples, up to $96 \%$ yield up to $>99 \%$ ee, all > 20:1 $d r$

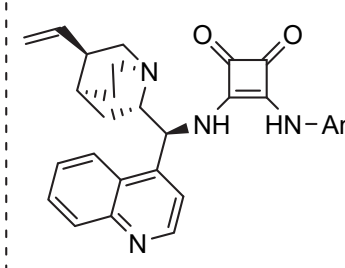

$\mathrm{Ar}=3,5-\left(\mathrm{CF}_{3}\right)_{2} \mathrm{C}_{6} \mathrm{H}_{3}$

C18

\section{Representative examples}

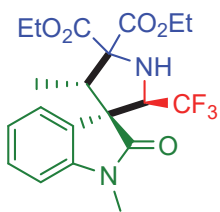

51a, $91 \%$ yield $>99 \%$ ee, > 20:1 dr<smiles>CCOC(=O)C1(C(=O)OCC)N[C@@H](C(F)(F)F)[C@]2(C(=O)N(Cc3ccccc3)c3ccccc32)[C@H]1C</smiles>

51d, $76 \%$ yield $94 \%$ ee, $>20: 1 d r$

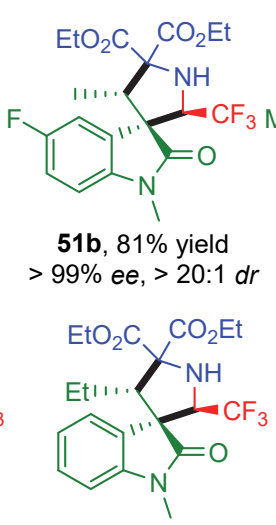

51e, $83 \%$ yield $>99 \%$ ee, $>20: 1 d r$<smiles>CCOC(=O)C1(C(=O)OCC)N[C@@H](C(F)(F)F)[C@]2(C(=O)N(C)c3ccc(I)cc32)[C@H]1C</smiles>

51c, $91 \%$ yield $>99 \%$ ee, $>20: 1 d r$<smiles>CCOC(=O)C1(C(=O)OCC)N[C@@H](C(F)(F)F)[C@]2(C(=O)N(C)c3ccccc32)[C@H]1c1ccccc1</smiles>

51f, $65 \%$ yield $53 \%$ ee, $>20: 1 d r$

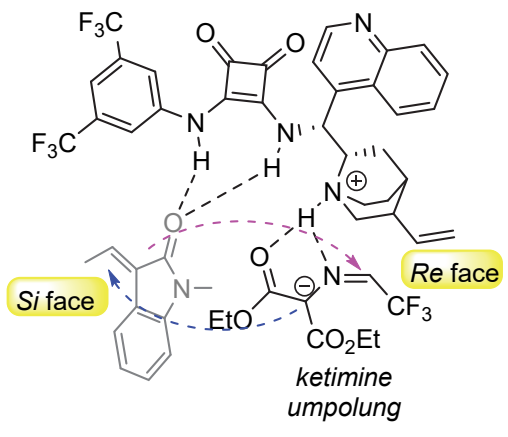

图式 20 催化酮亚胺极性反转的不对称 $[3+2]$ 环加成反应

Scheme 20 Catalytic asymmetric umpolung and [3+2] cycloaddition of ketimines

饱和醛 15 之间的不对称串联 Michael/Mannich[3+2]环 加成反应(Scheme 21). 在相同催化策略和温和的条件 下, 均可顺利地获得手性 $\alpha-\mathrm{CF}_{3}$ 四氢吡咯衍生物 52, 为 对映选择性构建复杂高度官能团化的吡咯烷骨架提供 了全新策略. 2017 年, Enders 等 ${ }^{[28]}$ 又将 $\beta$-硝基烯 17 作为 $2 \pi$ 体系, 实现了其与三氟乙基酮亚胺 12 间的有机催化 Michael/aza-Henry[3+2]环加成反应(Scheme 21), 进一 步丰富和拓展了手性多取代吡咯烷的合成方法.

2019 年，间文锦和王凯荣等 ${ }^{[29]}$ 报道了三氟乙基酮 亚胺 12 与 5-烯基噻唑酮 54 间的不对称 $[3+2]$ 环加成反
应(Scheme 22), 首次发展了有机催化构建含三氟甲基 的手性螺环吡咯烷一噻唑酮骨架的方法. 该方法催化剂 负载量仅为 $1 \mathrm{~mol} \%$ 时, 即可高效地催化环加成反应顺 利发生. 但在最优催化条件下，5-烯基噻唑酮双键 $\beta$-位 的取代基为芳基时，反应表现出良好的普适性，均可以 优秀的对映选择性获得螺环吡咯烷一噻唑酮类化合物 55. 但是，当 $\beta$-位的取代基脂肪烃基时，反应不发生.

鲁桂课题组 ${ }^{[30]}$ 近期报道了一类合成含三氟甲基的 手性螺环噁唑烷化合物 57 与 1,2-氨基醇 58 的新型有机 催化策略, 该方法以叔胺-硫脲催化剂 $\mathbf{C 2 0}$ 作为催化剂, 


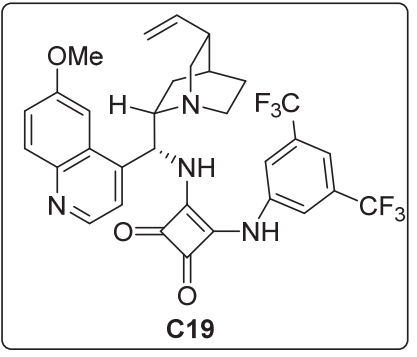

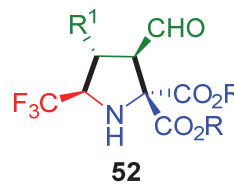

52

17 examples up to $98 \%$ yield up to $>99 \%$ ee all $>20: 1 d r$<smiles>[R]OCC1(CO[R])N[C@H](C(F)(F)F)[C@@H]([R1])[C@H]1C=O</smiles>

17

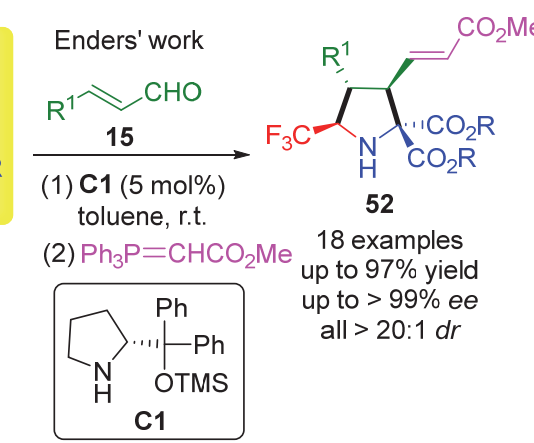

图式 21 有机催化三氟乙基酮亚胺不对称环加成反应构建手性吡咯烷

Scheme 21 Asymmetric construction of chiral pyrrolidines via organocatalytic cycloaddition of trifluoroethylfluorene ketimines
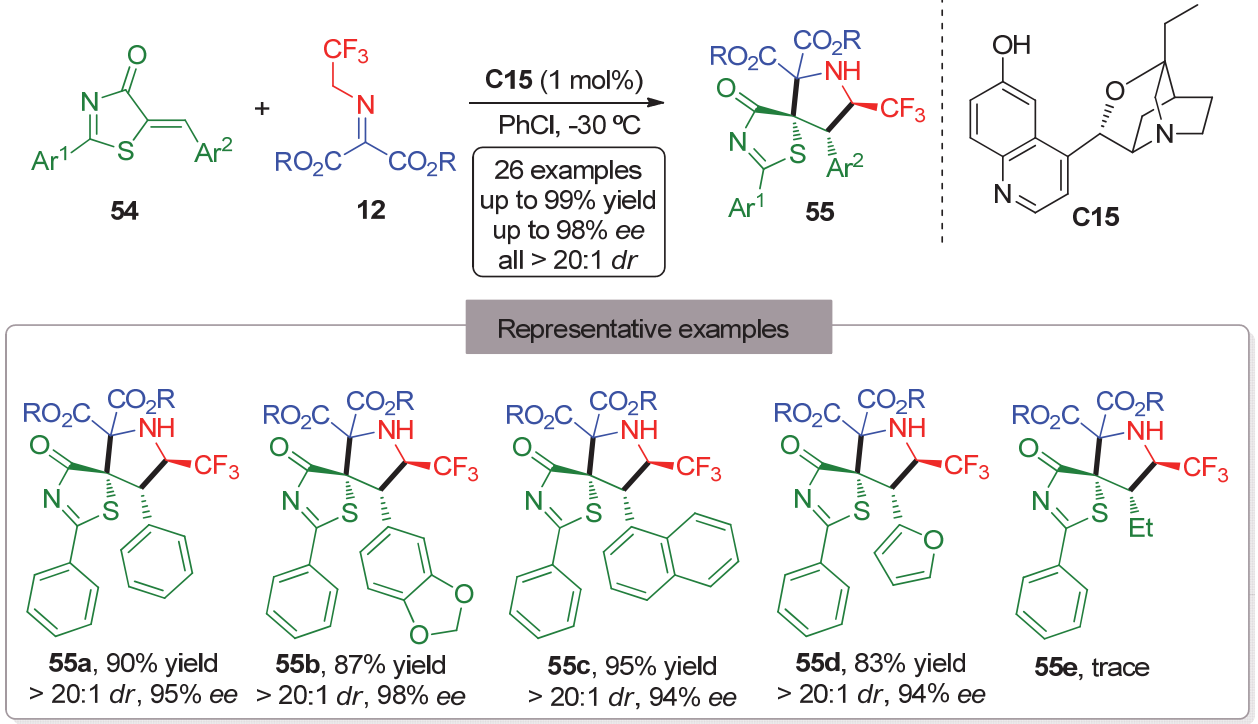

图式 22 催化不对称 $[3+2]$ 环加成反应构建手性螺环吡咯烷-噻唑酮化合物

Scheme 22 Construction of chiral spiro-thiazolone-pyrrolidine compounds via catalytic asymmetric [3+2] cycloaddition

可顺利催化三氟乙基酮亚胺 12 与靛红 9 和吡唑啉酮 56 等羰基化合物发生环加成反应(Scheme 23). 在最佳催 化条件下，该反应表现出对底物取代基类型和电性良好 的耐受性, 可以最高 $98 \%$ 的产率、最高 $98 \%$ ee 值和全部 $>20: 1 d r$ 值的立体选择性获得目标产物. 值得注意的 是，作者通过控制实验证实丙二酸酯-三氟乙基酮亚胺 12 结构中的双酯基团对于该类型的环加成反应的顺利 发生至关重要, 同时利于进一步转化为手性 1,2-氨基醇.

\section{4 总结和展望}

综上所述，三氟乙基酮亚胺作为具有优良活性的
1,3-偶极子、亲核试剂以及含有三氟甲基的合成砌块被 广泛应用于催化不对称反应之中，用于构建结构新颖、 复杂的手性有机杂环骨架与手性三氟乙胺分子. 到目前 为止, 国内外多个课题组围绕着有机催化的三氟乙基酮 亚胺不对称环加成反应而展开的合成方法学研究主要 集中在 $[3+2]$ 环加成反应，[3+1]和 $[3+3]$ 环加成的研究 工作相对较少, 而可用于构建大环的 $[4+3]$ 环加成的研 究还未曾涉及, 特别是将发展的合成方法学应用到活性 药物分子或复杂天然产物的合成更是鲜有报道. 随着有 机合成研究工作的深入, 在各类型手性有机催化剂作用 下进一步探索和拓展三氟乙基酮亚胺的环加成反应并 


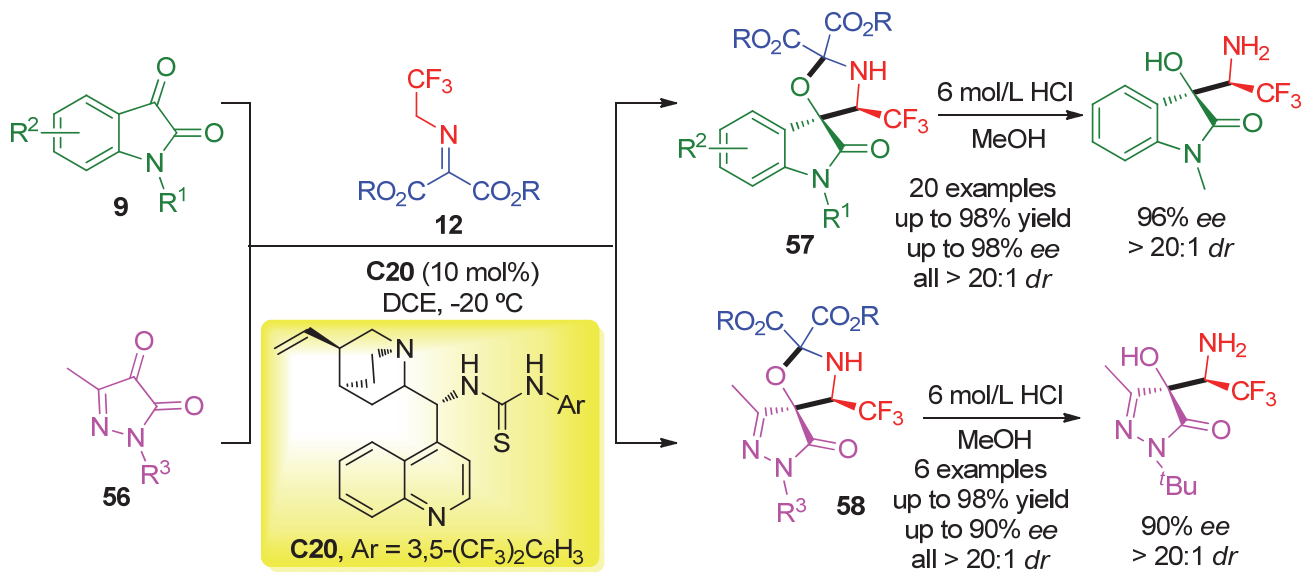

图式 23 有机催化酮亚胺与羰基化合物的不对称 1,3-偶极环加成反应

Scheme 23 Organocatalytic asymmetric 1,3-dopolar cycloaddition of ketimines with carbonyl compounds

将其应用于构建活性药物分子或其骨架，甚至将其应用 于天然产物分子的合成研究将成为今后研究的热点和 具有挑战性的研究课题. 相信通过科研工作者的努力, 将可开发出更加丰富的有机催化体系，拓展三氟乙基酮 亚胺参与的各式各样的反应类型, 进一步推动不对称合 成的发展.

\section{References}

[1] (a) Furuya, T.; Kamlet, A. S.; Ritter, T. Natrue 2011, 473, 470.

(b) Merino, F.; Nevado, C. Chem. Soc. Rev. 2014, 43, 6598

(c) Usachev, B. I. J. Fluorine Chem. 2015, 175, 36.

(d) Huang, S.-C.; Schlinquer, C.; Poisson, T.; Pannecoucke, X.; Charette, A. B.; Jubault, P. Chem.-Eur. J. 2018, 24, 10339.

(d) He, X.-H.; Ji, Y.-L.; Peng, C.; Han, B. Adv. Synth. Catal. 2019, $361,1923$.

[2] (a) Corbett, J. W.; Ko, S. S.; Rodgers, J. D.; Gearhart, L. A.; Magnus, N. A.; Bacheler, L. T.; Diamond, S.; Jeffrey, S.; Klabe, R. M.; Cordova, B. C.; Garber, S.; Logue, K.; Trainor, G. L.; Anderson, P. S.; Erickson-Viitanen, S. K. J. Med. Chem. 2000, 43, 2019.

(b) Jlalia, I.; Lensen, N.; Chaume, G.; Dzhambazova, E.; Astasidi, L.; Hadjiolova, R.; Bocheva, A.; Brigaud, T. Eur. J. Med. Chem. 2013, 62, 122.

(c) Liu, Y.; Chen, J.-L.; Wang, G.-H.; Sun, P.; Huang, H.; Qing, F.-L. Tetrahedron Lett. 2013, 54, 5541.

(d) Guillaume, M.; Benoit, C.; Sebastien, C.; Philippe, G.; Pierre, B. J.; Daniele, B. D. J. Med. Chem. 2004, 47, 2694.

(e) Nie, J.; Guo, H.-C.; Cahard, D.; Ma, J.-A. Chem. Rev. 2011, 111, 455 .

[3] (a) Timperley, C. M. Waters, M. J. Fluorine Chem. 2005, 126, 1144.

(b) Morandi, B.; Carreira, C. M. Angew. Chem., Int. Ed. 2010, 49, 119.

(c) Morandi, B.; Mariampillai, B.; Carreira, C. M. Angew. Chem., Int. Ed. 2011, 50, 1101.

(d) Li, F.; Nie, J.; Dun, L.; Zheng, Y.; Ma, J.-A. Angew. Chem., Int. Ed. 2013, 52, 6255.

(e) Molander, G. A.; Ryu, D. Angew. Chem., Int. Ed. 2014, 53, 14181.

(f) Brusoe, A. T; Hartwig, J. F.J. Am. Chem. Soc. 2015, 137, 8460.

(g) Li, S.; Cao, W.-J.; Ma, J.-A. Synlett 2017, 28, 673.

(h) Kotozaki, M.; Chanthamath, S.; Fujii, T.; Shibatomi, K.; Iwasa,

S. Chem. Commun. 2018, 54, 5110.

(i) Zhang, X.-W.; Hu, W.-L.; Chen, S.; Hu, X.-G. Org. Lett. 2018, 20,860 . (j) Gui, H.-Z.; Wei, Y.; Shi, M. Chem.-Asian J. 2020, 15, 1225.

[4] Ma, M.-X.; Zhu, Y.-Y.; Sun, Q.-T.; Li, X.-Y.; Su, J.-H.; Zhao, L.; Zhap, Y.-Y.; Qiu, S.; Yan, W.-J.; Wang, K.-R.; Wang, R. Chem. Commun. 2015, 51, 8789.

[5] Zhi, Y.; Zhao, K.; Liu, Q.; Wang, A.; Enders, D. Chem. Commun. 2016, 52, 14011 .

[6] Dong, Z.-H.; Zhu, Y.-Y.; Li, B.-Y.; Wang, C.; Yan, W.-J.; Wang, K.-R.; Wang, R. J. Org. Chem. 2017, 82, 3482.

[7] Sun, Q.-T.; Li, X.-Y.; Su, J.-H.; Zhao, L.; Ma, M.-X.; Zhu, Y.-Y.; Zhao, Y.-Y.; Zhu, R.-R.; Yan, W.-J.; Wang, K.-R.; Wang, R. Adv. Synth. Catal. 2015, 357, 3187.

[8] You, Y.; Lu, W.-Y.; Wang, Z.-H.; Chen, Y.-Z.; Xu, X.-Y.; Zhang, X.-M.; Yuan, W.-C. Org. Lett. 2018, 20, 4453.

[9] Gao, X.-Y.; Yan, R.-J.; Xiao, B.-X.; Du, W.; Albrecht, L.; Chen, Y.-C. Org. Lett. 2019, 21, 9628.

[10] Zhou, C.-C.; Han, Y.-Y.; Zeng, C.-K.; Zhang, T.-Y.; Ye, J.-X. Chin. Chem. Lett. 2020, 31, 377.

[11] Choudhury, A. R; Mukherjee, S. Chem. Soc. Rev. 2020, 49, 6755.

[12] Wang, Z.-H.; Wu, Z.-J.; Yue, D.-F.; Hu, W.-F.; Zhang, X.-M.; Xu, X.-Y.; Yuan, W.-C. Chem. Commun. 2016, 52, 11708.

[13] (a) Song, Y.-X.; Du, D.-M. J. Org. Chem. 2018, 83, 9278.

(b) Lin, Y.; Song, Y.-X.; Du, D.-M. Adv. Synth. Catal. 2019, 361, 1064.

(c) An, T.-L.; Du, D.-M. ChemistrySelect 2019, 4, 11302.

[14] (a) Li, B.-Y.; Gao, F.-Y.; Feng, X.; Sun, M.-M.; Guo, Y.-F.; Wen, D.-W.; Deng, Y.-B.; Huang, J.-Q.; Wang, K.-R.; Yan, W.-J. Org. Chem. Front. 2019, 6, 1567.

(b) Wang, C.; Wen, D.-W.; Chen, H.; Deng, Y.-B.; Liu, X.-T.; Liu, X.; Wang, L.; Gao, F.-Y.; Guo, Y.-F.; Sun, M.-M.; Wang, K.-R.; Yan, W.-J. Org. Biomol. Chem. 2019, 17, 5514.

[15] Zhao, X.-Y.; Xiong, J.-L.; An, J.-K.; Yu, J.-C.; Zhu, L.-P.; Feng, X.; Jiang, X.-X. Org. Chem. Front. 2019, 6, 1989.

[16] Liu, X.; Lu, D.-M.; Wu, J.-H.; Tan, J.-P.; Jiang, C.-H.; Gao, G.-W.; Wang, T.-L. Adv. Synth. Catal. 2020, 362, 1490.

[17] (a) Sun, Q.-S.; Zhu, H.; Chen, Y.-J.; Yang, X.-D.; Sun, X.-W.; Lin, G.-Q. Angew. Chem., Int. Ed. 2015, 54, 13253.

(b) Zhu, L.-Y.; Chen, Q.-L.; Shen, D.; Zhang, W.-H.; Shen, C.; Zeng, X.-F.; Zhong, G.-F. Org. Lett. 2016, 18, 2387.

(c) Ren, J.-W.; Wang, J.; Xiao, J.-A.; Li. J.; Xiang, H.-Y.; Chen, X.-Q.; Yang, H. J. Org. Chem. 2017, 82, 6441.

(d) Yang, Q.-Q.; Xiao, W.; Du, W.; Qin, Q.-Y.; Chen, Y.-C. Chem. Commun. 2018, 54, 1129.

(e) Wang, C.-Y.; Wang, Z.-Y.; Yang, J.; Shi, S.-H.; Hui, X.-P. Org. Lett. 2020, 22, 4440.

[18] (a) Huang, W.-J.; Chen, Q.; Lin, N.; Long, X.-W.; Pan, W.-G.; Xiong, Y.-S.; Weng, J.; Lu, G. Org. Chem. Front. 2017, 4, 472. (b) Zhi, Y.; Zhao, K.; Essen, C. V.; Rissanen, K.; Enders, D. Synlett 2017, 28, 2876. 
(c) Zhao, B.-L.; Du, D.-M. Adv. Synth. Catal. 2019, 361, 3412.

(d) Li, Yang, Hua, Y.-Z.; Lu, H.-J.; Liu, L.-T.; Wan, M.-C. Org. Lett. 2020, 22, 2527.

[19] Zhu, W.-R.; Zhang, Z.-W.; Huang, W.-H.; Lin, N.; Chen, K.-B.; Wang, B.-C.; Weng, J.; Lu, G. Synthesis 2019, 51, 1969.

[20] Li, X.-Y.; Sun, J.-H.; Liu, Z.-R.-J.; Zhu, Y.-Y.; Dong, Z.-H.; Qiu, S.; Wang, J.-Y.; Lin, L.; Shen, Z.-Q.; Yan, W.-J.; Wang, K.-R.; Wang, R. Org. Lett. 2016, 18, 956.

[21] Shi, L.-M.; Sun, X.-S.; Chen, C.; Wang, Z.-F.; Tao, H.-Y.; Wang, C.-J. Org. Lett. 2019, 21, 4842.

[22] Onywagusi, C. I.; Shao, X.-X.; Malcolmson, S. J. Org. Lett. 2020, $22,681$.

[23] Zhu, W.-R.; Liu, K.; Weng, J.; Huang, W.-H.; Huang, W.-J.; Chen, Q.; Lin, N.; Lu, G. Org. Lett. 2020, 22, 5014.

[24] (a) Zhu, Y.; Buchwald, S. L. J. Am. Chem. Soc. 2014, 136, 4500. (b) Liu, J.; Cao, C.-G.; Sun, H.-B.; Zhang, X.; Niu, D.-W. J. Am. Chem. Soc. 2016, 138, 13103.
[25] (a) Wang, Y.-W.; Deng, L.-F.; Zhang, X.; Niu, D.-W. Org. Lett. 2019, 21, 6951.

(b) Shen, C.; Wang, R.-Q.; Wei, L.; Wang, Z.-F.; Tao, H.-Y.; Wang, C.-J. Org. Lett. 2019, 21, 6940.

[26] Wang, W.; Xiong, Q.; Gong, L.; Wang, Y.-W.; Liu, J.; Lan, Y.; Zhang, X. Org. Lett. 2020, 22, 5479.

[27] Sun, J.-H.; Ma, Z.-L.; Li, X.-Y.; Li, L.; Shen, Z.-Q.; Yang, P.-J.; Li, Y.; Wang, H.-L.; Yan, W.-J.; Wang, K.-R.; Wang, R. Adv. Synth. Catal. 2016, 358, 3777.

[28] Liu, Q.; Zhao, K.; Zhi, Y.; Raabe, G.; Enders, D. Org. Chem. Front. 2017, 4, 1416.

[29] Li, B.-Y.; Liu, J.-K.; Gao, F. Y.; Sun, M.-M.; Guo, Y.-F.; Zhou, Y.; Wen, D.-W.; Deng, Y.-B.; Chen, H.; Wang, K.-R.; Yan, W.-J. Org. Biomol. Chem. 2019, 17, 2892.

[30] Zhu, W.-Y.; Su, Q.; Lin, N.; Chen, Q.; Zhang, Z.-W.; Weng, J.; Lu, G. Org. Chem. Front. 2020, 7, 3452.

(Cheng, F.) 